\title{
PART I:
}

\section{CLIMATE CHANGE AND ENERGY}




\title{
Chapter 2: \\ Climate change legislative development on the African continent
}

\author{
Olivia Rumble
}

Global warming as a result of climate change is no longer a future threat, but an experienced reality in many countries. Partly because of its lower adaptive capacity, some of the worst impacts of climate change will be experienced in Africa, even though its contribution to the problem is disproportionately low. ${ }^{1}$ Anticipated impacts include more intense and frequent droughts, heat stress, tropical cyclones, and flooding. The sectors which are particularly vulnerable to its many impacts include water, agriculture and human health. Not only does climate change have the potential to affect the realisation of human rights negatively, ${ }^{2}$ it is also expected to be a significant disruptor to developmental aspirations such as poverty reduction, job creation, and inclusive and equitable macroeconomic growth. As a threat multiplier, climate change also has widereaching economic and security impacts on governance through its ability to exacerbate existing trends, tensions and instability, for example in the form of increased tensions over scarce resources, border disputes, energy conflicts and conflict prompted by migration. ${ }^{3}$ For these reasons, adaptation is a priority area for policymakers on the continent, and the African Union has urged all member states to put in place systems

1 UNECA (2017). The article comments on investigations which suggest that the public expenditure on adaptation as a percentage of the overall adaptation costs for African countries is approximately $20 \%$ of total needs, ranging between 2 and $9 \%$ of the GDP. This demonstrates that African countries are already investing a higher percentage of finances in adaptation spending than international financial support. It confirms that these countries are already making major contributions to adaptation efforts and related expenditure.

2 There are numerous studies on the linkages between climate change and human rights. See for example OHCHR (2009) and Knox (2009). The OHCHR noted that climate change threatens the enjoyment of a wide array of human rights, although it does not in itself necessarily violate human rights. That notwithstanding, human rights law places duties on states concerning climate change and those duties include an obligation of international cooperation. Examples of affected human rights include the right to life, health, privacy, property as well as components of the right to an adequate standard of living.

3 See IPCC (2014: 1203) where it is stated that "climate change and climate variability have the potential to exacerbate or multiply existing threats to human security including food, health, and economic insecurity, all being of particular concern for Africa... Many of these threats are known drivers of conflict". 
and structures to take full advantage of the global mechanisms in support of climate change mitigation and adaptation. ${ }^{4}$

The extent of the current and anticipated impacts necessitates the implementation of comprehensive and costly adaptive measures by national governments in Africa. These have been proven to be difficult. The most recent Intergovernmental Panel on Climate Change Fifth Assessment Report (AR5), highlights that national governments across the continent have initiated governance systems for adaptation responses, however, as of yet, evolving institutional frameworks are unable to coordinate the range of adaptation initiatives being implemented effectively. ${ }^{5}$ It was concluded that whilst there had been progress on national and subnational strategies and policies in starting to mainstream adaptation into sectoral planning, there was "incomplete, under-resourced, and fragmented institutional frameworks and overall low levels of adaptive capacity" to manage highly complex socio-ecological changes. ${ }^{6}$ This resulted in reform being driven by reactive, ad-hoc and project orientated approaches, which were donor-funded in many cases. ${ }^{7}$

Not only must governments plan for adaptive measures, but they must mitigate greenhouse gases (GHGs). The Paris Agreement now requires all countries to participate in a global mitigation effort to reduce the impacts of GHG emissions and to achieve a long-term temperature goal of below 2 degrees centigrade. ${ }^{8}$ All parties are required to make a fair contribution to this effort and must submit Nationally Determined Contributions (NDCs), which address both adaptation and mitigation actions, successive versions of which must be increasingly more ambitious. The NDCs must set out what these national contributions entail, and governments are obliged to pursue domestic GHG mitigation measures with the aim of achieving the objectives of these contributions. ${ }^{9}$ The Paris Agreement specifically provides that developing countries, which includes most of Africa, are required to continue enhancing their GHG mitigation efforts and are encouraged to move over time towards economy-wide GHG emissions reduction or limitation targets. ${ }^{10}$

While African countries collectively have a relatively low GHG emissions profile, many countries on the continent have a wealth of opportunities for the deployment of

4 CAHOSCC (2014). This framework programme was adopted at the 23rd Ordinary Session of the Summit of the African Union in Malabo, Equatorial Guinea, and it reaffirms that adaptation is a priority in all actions on climate change in Africa.

$5 \quad \operatorname{IPCC}(2014: 1203)$.

6 Ibid.

7 Ibid. It was found that "[d]isaster risk reduction, social protection, technological and infrastructural adaptation, ecosystem-based approaches, and livelihood diversification are reducing vulnerability, but largely in isolated initiatives".

8 In addition to this goal it was agreed that countries would pursue efforts to limit the temperature increase to 1.5 degrees Celsius (Article 2(1)(a) of the Paris Agreement).

9 Article 4(2) of the Paris Agreement.

10 Article 4 of the Paris Agreement. This is subject to the qualification that this obligation is subject to different national circumstances. 
renewable energy and related co-benefits, given the maturity of their energy sectors. ${ }^{11}$ Indeed, 53 of the 54 African NDCs submitted under the Paris Agreement included renewable energy as part of their mitigation ambitions. ${ }^{12}$ Whilst low carbon development is indeed an opportunity, the effective implementation of a medium to long-term low carbon development strategy is often underpinned by a host of strategic, financial and legal considerations which governments need to be attuned to. Similarly, decisions related to the exploitation of the continent's abundant natural resources, many of which result in the release of GHGs, will need to be guided by domestic financial, legal and related strategic considerations, taking into account the country's relevant commitments under its NDC.

These challenges, opportunities and interactions paint a complex picture of the scale and complexity of responding to climate change at a national level. An effective response will require a nationally led and coordinated effort which goes beyond what has traditionally been perceived as the terrain of 'environmental' governance, to almost every sector of national government, including energy and industry, transport, trade, human settlements and migration, health, agriculture and fisheries, mining and water. This precipitates the need for cross-sectoral governance, levels of cooperation, and forward planning at a national, regional and international level at a hitherto unknown scale. In the midst of this response, the law plays an important mediating and empowering role.

To date, policy and strategy have largely directed government action on the continent. This may be symptomatic of the equivocality in the international legal regime over the past decade. The finalisation and adoption of the Paris Agreement at the 21st Session of the Conference of the Parties to the United National Framework Convention on Climate Change (UNFCCC), however, constitute a turning point in the international negotiations. For the first time in history, all countries have publicly committed to taking action on mitigating GHG emissions and responding to the impacts of climate change. The domestic legal systems of each member state will play a critical role in implanting the commitments made by each party. ${ }^{13}$

Interestingly, since the conclusion of the Paris Agreement, many African countries have developed, or are in the process of developing, dedicated climate change laws, or amendments to existing laws that take into account climate change considerations. Most of these initiatives build on existing climate change policies and the NDCs devised in accordance with the Paris Agreement. Current legislative initiatives include

11 In other words, they are not subject to the same technological and energy development "lockin" that other more developed countries are.

12 Phillips (2016) quoting Abdalla Hamdok, Chief Economist and Deputy Executive Secretary of the United Nations Economic Commission for Africa. It has been speculated that the Paris Agreement could be the catalyst for new investment drivers for structural transformation in Africa to achieve low carbon development.

Averchenkva \& Matikamen (2017: 193). 
the Kenyan Climate Change Act 11 of 2016, which was promulgated in May 2016, and the regulations under the South African National Environmental Management: Air Quality Act 39 of 2004, published in 2017. South Africa is also in the process of finalising a draft Carbon Tax Bill and a separate draft Climate Change Bill. In addition, Uganda, Zambia, Rwanda and Nigeria are all either in the process of debating in parliament legislative mechanisms to respond to climate change or have also implemented partial legislative reforms to respond to climate change impacts.

To date, there has been little academic discussion of these developments and what they might mean for African countries in particular. This chapter seeks to provide an overview of some of these legislative reforms, specifically those in South Africa and Kenya, to distil whether there are any lessons or examples of best practice for other African countries currently debating whether to introduce such reforms.

The chapter begins with a discussion on the role of law in responding to climate change, the meaning of 'climate change legislation' and the status of this legislation in Africa. This discussion is followed by an overview of how two African countries, Kenya and South Africa, have approached this challenge and the different legal frameworks they have adopted or are in the process of adopting to address their unique domestic needs. The analysis considers whether there are any possible lessons to be learnt from these legislative responses which will aid other African countries in assessing the adequacy of their existing laws to respond to climate change, and amending or introducing new laws in response. The complexity of the required legal response cannot be ignored. The need for tailored legislative responses to unique domestic situations cannot be overridden by simplistic 'quick fix' legislative solutions. Baring this in mind, the purpose of this chapter is to provide examples of possible legal options to African countries who wish to introduce climate change legislation, in a nascent area of law that is rapidly evolving.

Compared to the dynamic and evolving policy and strategic climate change responses developed by governments to date, the law is a relatively cumbersome and static medium to address climate change. It is often reactive, responding to different challenges and impacts as they arise, typically in response to defined and known problems. In the case of climate change, the extent of the challenge is only now being experienced, and the required response is anticipatory in nature. Yet legislative mechanisms can and do play a critical role in empowering governments to take action, creating certainty; powerful incentives and disincentives; structures; institutions; and mechanisms to facilitate a more co-ordinated, effective and mandatory response.

The importance of law in regulating a climate change response is evident in the upswing of climate change laws over the last two decades. This is partially attributable 
to the dynamism in the international negotiations on climate change (domestic laws typically follow the enactment of international agreements in order to support implementation) but also a growing appreciation of the crucial role that domestic laws and measures play. ${ }^{14}$ The first law to expressly regulate climate change was passed by Japan in $1998 .{ }^{15}$ Since then there was a slow increase in laws with a flurry in 2009 and $2010,{ }^{16}$ likely ascribable to the international political factors around the Copenhagen negotiations in 2009. The introduction of such laws then fell again, largely as a result of inertia in the international negotiations, challenging macroeconomic environments and the fact that most developed (Annex 1) countries had introduced relatively comprehensive climate change laws. ${ }^{17}$ Since then, the legislative momentum moved towards developing (non-Annex 1) countries. ${ }^{18}$

The Grantham Institute's annal on the status of climate change legislation and litigation has been a consistent gauge of the rise of climate laws worldwide. Its latest publication in 2017 posited that there were now more than 1,200 climate change or climate change-relevant laws across the world, which according to their records was a twenty-fold increase in the last twenty years. ${ }^{19}$ Approximately $44 \%$ of the instruments used in their research are legislative acts of parliament. ${ }^{20}$

While many have sought to track this development, it is difficult to arrive at a consensus of what exactly 'climate change legislation' is. Low carbon and climate resilient development require a combination of technical, social, cultural and management change, and the law plays a fundamental role in facilitating these changes. The peculiar nature of climate change, its complexity, uncertainty, relative novelty as a global phenomenon and scale in terms of space and time, make it challenging to regulate. Climate change has been described as a 'wicked' problem: it has enormous interdependencies, uncertainties, and conflicting stakeholders resulting in the inability to formulate a single problem or solution. ${ }^{21}$ Furthermore, the more time it takes to address the more difficult it becomes, while those who are well placed to respond have the least incentive to act, making its governance a complex reality. Climate change is also interlinked with numerous policy issues which are often already regulated by other laws, such as energy, transport, industrial policy, forestry and land use, biodiversity, water, air quality, poverty and food security. ${ }^{22}$ Any legislative response needs to take into account these linkages, either by adding further layers to existing legislation or through

14 Oulu (2015: 230).

15 Japan's Law Concerning the Promotion of the Measures to Cope with Global Warming (1998).

16 Townshend et al. (2013: 430).

17 Ibid.

18 Fankhauser et al. (2014).

19 Nachmany et al. (2017: 5).

20 Ibid: 8.

21 Lazarus (2008: 1153).

22 Nachmany et al. (2017: 10). Sectors of biodiversity and water have been added to the list set out by the Grantham Institute. 
enacting a separate climate change law. ${ }^{23}$ In sum, there are no basic minimum requirements which climate change legislation is required to address, and there is no easy definition of what it entails.

In 2011, Townshend et al. used the term climate change 'Flagship Laws' to mean "a key piece of legislation through which lawmakers have attempted to put their stamp on climate change policy", ${ }^{24}$ and again used the term in 2013 to mean "a piece of legislation or regulation with equivalent status that serves as a comprehensive unifying basis for climate change policy". ${ }^{25}$ Such flagship laws were described as "often [being] integrative laws that bring together the various strains of pre-existing and new climate change regulation under one legislative umbrella, as has occurred in Brazil, France, South Korea and the United Kingdom". ${ }^{26}$ Townshend argued that the five-year plans in China and India served a similar purpose. ${ }^{27}$ The Grantham Research Institute has expanded upon this definition of 'Flagship Laws' to retain its original scope but to add to its content and rename it as 'framework laws'. The latter represents a law or regulation with an equivalent status which serves as a comprehensive, unifying basis for climate change policy which addresses multiple aspects or areas of climate change mitigation or adaptation (or both) in a holistic and overarching manner. ${ }^{28}$ Typical examples provided in their study include the United Kingdom's Climate Change Act (2008); Bulgaria's Climate Change Mitigation Act (2014); Denmark's Climate Change Act (2014) and Mexico's General Law on Climate Change (2012). The database, however, also includes much wider policy instruments under the 'framework laws' heading, such as Slovakia's National Adaptation Strategy (2014) and Germany's Action Programme on Climate Protection (2014). ${ }^{29}$ This chapter does not seek to address the appropriateness of the inclusion of policy in this working definition. ${ }^{30}$ For the purpose of this analysis, the author uses the term 'framework law' to represent an act of parliament or equivalent authority having binding legal effect at a national (as opposed to provincial or local) level, which does not include policies, strategies, plans

23 Ibid.

24 Townshend et al. (2011: 6).

25 Townshend et al. (2013: 430).

26 Townshend et al. (2011: 9).

27 Ibid.

28 Nachmany et al. (2015: 20).

29 Ibid: 17.

30 The Grantham Research Institute justifies the approach on the basis that different countries use different routes to address climate change and they have different regulatory traditions and local contexts. For example, China has a strong executive branch which governs by policy whilst the UK has a strong Parliamentary tradition. They also acknowledge that executive activity may reflect an early phase in climate policy development where policies have not yet matured into formal legislation or legislative capacities are insufficient. Their reports distinguish between legislative acts passed by a parliament or equivalent legislative authority and executive instruments (e.g. presidential degrees, executive orders, government policies or plans) passed or decreed by the government, president or equivalent executive authority. Where both existed, prominence was devoted to legislative acts, see Nachmany et al. (2015: 30). 
or similar documents. The reason for doing so is the author's belief that not only is legislation in certain cases more appropriate, for example where it relates to decisions which curtail or limit existing rights, but also because of the binding and enduring nature of legislation over policy.

So-called framework laws, or 'overarching' legislative approaches are not the only means of regulating climate change. As mentioned above, legislators have also followed an approach which focuses on specific areas of law and the statutes which directly regulate those areas of law. This approach is referred to in this chapter as the 'sectoral' approach. ${ }^{31}$ For example, legislators can 'climate proof' existing energy legislation, by adding further layers to it which speak directly to the mitigation of GHGs only. Surveys of these amendments indicate that amendments to energy law frameworks are the most popular. ${ }^{32}$ A further distinction under the sectoral approach is that some prefer a process of statutory amendment through parliament or equivalent authority, whilst other countries prefer to use a regulative approach, i.e. through the executive. For example, after failing to pass bespoke legislation the United States' executive government developed regulations under the Clean Air Act 1970 for GHG emissions.

While there is no best practice set of climate change legislative principles, there are some compelling arguments on both sides on whether a framework law or a sectoral approach is more effective or appropriate. On the one hand, as Oulu argues, despite being constrained by time and resource requirements, a stand-alone framework law is preferable to piecemeal amendments to relevant laws. ${ }^{33} \mathrm{He}$ draws this conclusion on the basis that -34

(i) the 'wicked' nature of climate change requires strategies and policy instruments that go beyond what existing sectoral legislation might have been conceived to deal with, and

(ii) the nature and degree of potential amendments to existing sectoral laws are so extensive that they are best captured in comprehensive stand-alone legislation.

As an example, he cites the experience in the United Kingdom of the initially limited Climate Change and Sustainable Energy Act (2006) which was expanded to become the more comprehensive Climate Change Act (2008).

In support of this approach, the Grantham Institute holds the view that not all laws are equal in importance and scope, and framework laws (which admittedly also includes overarching policies under their definition) have been shown to "encourage a strategic approach to climate policy and to generate further policy action". ${ }^{35}$

31 Nachmany et al. (2015: 10).

$3288 \%$ of countries in 2017 had an integration of climate change issues in energy policy, mostly focused on electrification, energy efficiency and conservation and renewable energy, see Nachmany et al. (2017: 12).

33 Nachmany et al. (2015: 22).

34 Oulu (2015: 245).

35 Nachmany et al. (2015: 17); and Fankhauser et al. (2014). 
Highlighting the important political statement that such laws can make and their resilience to political flux, Williams also notes that after Brexit in the United Kingdom, the domestic Climate Change Act (2008) was a robust instrument in the light of policy uncertainty, by providing a "continuous and consistent overarching framework which requires no primary amendment". ${ }^{36}$

It can also be more politically challenging to incorporate amendments across a broad suite of laws that address different sectors of the economy as it requires numerous Ministers to champion the passage of multiple amendments to the legislation applicable to their respective mandates. This makes framework laws more appetising from a parliamentary economy perspective.

An overarching framework law is also particularly conducive to the introduction of mechanisms and institutions to achieve specific climate change objectives. For example, the creation of a climate change institution such as a committee or forum (which is typical of many framework laws) depending on its powers and functions, can be a compelling platform for ensuring that cross-cutting, harmonised and coordinated decision making is made at the highest levels of government, and integrated across sectors. Whilst it is not always necessary to have laws to create or regulate these types of bodies, if they are to have meaningful powers and functions with statutory accountability, it is certainly preferable to empower and direct them through framework laws.

On the other hand, there are compelling arguments which support a sectoral approach where climate change considerations are incorporated into existing decision making and empowering provisions. Much of this turns on how mainstreaming is best achieved. The cross-cutting nature of climate change has seen mainstreaming being widely advocated as an important approach to its management. ${ }^{37}$ This recognises the need for climate change considerations to be included within the prevailing direction or processes adopted by government. This supports an approach whereby climate change considerations are 'layered' into existing processes through the inclusion of specific climate change considerations within relevant statutes and regulations. This can be achieved through a framework law or under a sectoral approach. Purely from a pragmatic perspective, a sectoral approach may better facilitate the mainstreaming since relevant authorities are often typically appraised of their powers and duties under sectoral laws relevant to their spheres of governance. It may be challenging to get administrators to learn a new set of laws, and for this reason alone it may be easier to incorporate climate considerations into statutes which they are familiar with implementing. Where there are capacity restraints, it can be particularly challenging to educate both the public and the administration on a new climate change law, in addition to the suite of laws the public and the administration are already required to abide by or implement. These challenges can be mitigated if existing and familiar laws are 
amended to take climate change considerations into account (i.e. to use a sectoral approach).

There are numerous benefits to both approaches which warrant further discussion and consideration. For the purpose of this chapter, the advantages of framework laws appear to outweigh a sectoral approach. However, the author is cognisant of the fact that each country will have individual requirements and unique climate change considerations which will require it to consider these merits and disadvantages. Perhaps, true to the so-called 'bottom-up' ${ }^{38}$ approach of the Paris Agreement, it is up to each country to tailor its legislative response to fit national circumstances, mindful that framework laws are a particularly useful approach. This chapter seeks to demonstrate the prevalence of national framework laws and related regulations on the continent in order to provide guidance on the possible options available to national governments of what they might address.

Before turning to this overview, and mindful of the nationally determined nature of such responses, it is also useful to consider some of the key objectives which climate change laws can address. The next section accordingly briefly discusses the way in which law can address the two key issues in climate change: the mitigation of GHG emissions; and the increase of resilience to the impacts of climate change (adaptation).

\subsection{Mitigation law}

Much of the public discourse relating to climate change governance has related to mitigation. ${ }^{39}$ The law can play a particularly important role in incorporating the mitigation aspects of NDCs under the Paris Agreement. It can do this by prescribing a binding emissions reduction target for the country (such as in the case of the United Kingdom's Climate Change Act). ${ }^{40}$ Alternatively, it can prescribe a process for determining this target and how it is to be achieved domestically. The latter may be a more appropriate approach mindful that the Paris Agreement envisages a 'ratcheting up' mechanism to require increasingly more ambitions contributions over time.

According to the Intergovernmental Panel on Climate Change (IPCC), ${ }^{41}$ the law plays a particularly important role in enabling governments to limit GHGs by Land Use (AFOLU), and land use planning where activity is often strongly influenced by

38 In terms of which domestic contributions to the international effort are determined based on country's nationally determined contributions instead of being prescribed at an international level.

39 Osofsky \& McAllister (2012).

40 The United Kingdom's Climate Change Act (2008) requires the Secretary of State to ensure that the United Kingdom's net carbon account of GHGs by the year 2050 is at least $80 \%$ lower than the 1990 baseline.

41 IPCC (2014: 1168). 
planning and provision, regulations/statutes. The law can also promote the diffusion and innovation of emerging technologies, and it can remove barriers to energy efficiency. Indeed, an effective mitigation response requires fundamental changes to domestic and international energy systems, bringing an entirely distinct field, energy law, into the discussion. ${ }^{42}$

\subsection{Adaptation law}

Often, traditional models of environmental, planning and related laws either do not address the complexities and uncertainties of climate change or behave as barriers to adequate adaptation. ${ }^{43}$ This has implications for a broad spectrum of sectoral laws such as land use planning regimes, human health systems, biodiversity conservation and the exploitation of natural resources.

In commenting on this issue, McDonald and Styles ${ }^{44}$ promote the incorporation of adaptive management in legal frameworks as a means of recognising the dynamism of natural systems and the importance of monitoring, review, and modification of projects, plans and activities in response to new understanding, as a result of climate change. ${ }^{45}$ They propose five mechanisms to achieving it: namely changing statutory objectives; requiring monitoring and evaluation of projects, plans and activities; staged approvals processes; conditional approvals and statutory triggers; and proportionate resource allocation models. In their view, the use of these flexibility mechanisms facilitates decision making to respond to the impacts of climate change, while continuing to provide a level of legal certainty.

In addition to principles of adaptive management generally, climate change impacts will require the state to develop new strategies and policies for avoiding and recovering from these negative effects and seizing and harnessing the benefits of adaptation actions. ${ }^{46}$ The development of such plans and strategies can be facilitated through statutes and regulations which require administrators and developers to undertake climate change vulnerability assessments at various junctures in the development and governance process and to develop plans to respond to these risks. This applies not only in the context of an Environmental Impact Assessments (EIAs) but across a wide spectrum of planning processes. For this reason, these can be individual plans, or there can be statutory requirements to undertake such assessments as part of existing planning

43 McDonald \& Styles (2014: 25) and Craig (2010: 9).

44 McDonald \& Styles (2014: 25).

45 Ibid. They noted in 2014, that, even though it is a dominant approach in natural resource management, it finds very little express mention in legal frameworks. 
requirements, such as local development plans for municipalities, national sector strategies, or in the EIA process itself.

Countries will, in any event, have to communicate in their NDCs under the Paris Agreement, a description of their adaptation goals, priorities, actions and needs. The Agreement also calls on countries to initiate processes to prepare and implement national adaptation plans. A priori, this will require countries to undertake vulnerability assessments across a wide range of vulnerable sectors, and the law can play an important role in ensuring that the requisite information is available to make submissions under the Paris Agreement. It can also play a guiding role in determining the content, timing and form of local assessments and plans.

The upswell of climate change laws internationally has also been experienced in Africa. An increasing number of African countries are in the process of developing or have already developed framework laws or sectoral amendments. Many of these initiatives advance the objectives and strategies in existing climate change policies and NDCs under the Paris Agreement. ${ }^{47}$

One of the more notable developments has been the Kenyan Climate Change Act which was promulgated in May 2016, as discussed in the sections which follow. In the same year, Zambia amended its Constitution to impose a duty on the State to "...establish and implement mechanisms that address climate change". ${ }^{48}$ The Zambian Green Party has petitioned Parliament to present a Bill on implementing Zambia's climate change commitments. ${ }^{49}$ In 2017, the party submitted a draft Bill to Parliament for consideration. ${ }^{50}$

In 2015, Uganda's Cabinet directed the Ministry of Water and Environment to create a framework law on climate change. Members of parliament were concerned about the delay in the enactment of legislation, which prompted them to give notice to government that further delay would result in draft legislation being introduced to parliament via a private member's Bill. ${ }^{51}$ In 2017, the Ministry published a call for proposals for a service provider to assist with the drafting of a Climate Change Bill, which included a complex scope of work as well as stakeholder consultation. ${ }^{52}$

In Nigeria, the House of Representatives initiated a Bill in 2017 which sought to establish a legal framework for the national climate change response and the formation

47 This summary is largely drawn from Gilder \& Rumble (2017: 268).

48 Gilder \& Rumble (2017: 268).

49 Arounusi (2017).

50 Ibid. Copies of this draft Bill are not publicly available for review by the author.

51 Gilder \& Rumble (2017: 268).

52 Ibid. 
of a National Council on Climate Change. ${ }^{53}$ According to reports, the proposed law is intended to be "holistic and overarching as it seeks to address both mitigation and adaptation efforts towards meeting NDC [objectives]". ${ }^{54}$ Furthermore, it will "pave way for a set of laws that will take care of sectoral challenges and targets" ${ }^{55}$ Recent reports suggest that trade unions, civil society organisations and academia have reviewed and been making inputs into a draft Climate Change Framework Bill. ${ }^{56}$

In addition to these framework laws, countries have also been adopting regulations and statues to address specific narrower climate change related issues. The Rwandan Parliament has enacted a law to improve the functioning of the Rwanda Green Fund (FONERWA) and its ability to mobilise climate finance. ${ }^{57}$ The law determines FONERWA's mission and organisation and defines how the climate financing institutional aspects will function.

In South Africa, regulations have also been developed to declare GHGs as priority pollutants under the National Environmental Management Air Quality Act 38 of 2004 (NEMAQA), and emitters are required to develop GHG mitigation plans and comply with GHG emissions reporting regulations. These regulations are discussed in further detail in the sections which follow. The Department of Environmental Affairs is also in the process of developing a Climate Change Bill which will ultimately incorporate these regulations and will also serve as a framework statute for the management of climate change impacts. In October 2017, the South African Parliamentary Environmental Affairs Portfolio Committee issued a statement confirming its support of a Climate Change Bill to be introduced in parliament. ${ }^{59}$ The National Treasury also published a draft Carbon Tax Bill for comment in December 2017 and stated that the actual date of implementation of the carbon tax would be determined through a separate and later process by the Minister of Finance through an announcement during 2018 or 2019 , taking into account the state of the economy.

The sections which follow provide a brief overview of the Kenyan and South African examples in order to highlight their salient features and discuss similarities and useful provisions.

53 Iroanusi (2017).

54 A copy of the draft Bill was not available for review at the time of drafting this chapter. All information has been obtained from Uwaegbulam (2016).

55 Uwaegbulam (2016).

56 Danmaryam (2017).

57 Tashobya (2017).

58 Act 39 of 2004.

59 Parliamentary Communication Services (2017). 
For more than a decade, South Africa has been formulating a comprehensive climate change response. The overarching policy directive is found in the White Paper on the National Climate Change Response Policy 2011 (NCCRP). The NCCRP builds on a series of policy statements and strategies including the National Climate Change Response Strategy (September 2004) ${ }^{60}$ and the Long-Term Mitigation Scenarios Document (2007). ${ }^{61}$ Since its publication, the NCCRP has been complemented by a range of related documents including the Mitigation Potential Analysis (2014); ${ }^{62}$ the LongTerm Adaptation Scenarios Report (LTAS, 2013 and 2015) ${ }^{63}$; the Intended Nationally Determined Contribution (2015) ${ }^{64}$ which has become the country's NDC under the Pairs Agreement; and two important draft documents, namely the Draft National Adaptation Strategy (2016) ${ }^{65}$ and the Draft Post-2020 Mitigation Scenarios Systems Report (2017). ${ }^{66}$ A series of regulations to address mitigation of GHGs have also been published (as discussed below). The Department of Environmental Affairs (Department) has also expressed an intention to develop a Climate Change Bill which will be in the form of a framework law. Since the Climate Change Bill has not been formally published for public comment yet, it is not possible to discuss its contents in detail for the purpose of this chapter. However, where possible, key elements of its likely content will be discussed.

Besides, the National Treasury also expressed its intention to implement a national carbon tax and to this end, it published a series of policies and strategies outlining the reason for the tax and proposing its intended content and scope, followed by two draft Carbon Tax Bills. Again, it is not possible to address the extensive detail of these regulatory provisions within the confines of this chapter. However, it is helpful to outline their key elements and how they are likely to relate to each other and evolve as they come into effect sequentially over the next five years.

\subsection{Mitigation framework}

In respect of mitigation, the South African Department of Environmental Affairs intends to address low carbon development in five distinct ways, entailing:

60 South African Department of Environmental Affairs (2004).

61 Winkler (2007).

62 South African Department of Environmental Affairs (2014).

63 South African Department of Environmental Affairs (2013) and Department of Environmental Affairs (2015).

64 Government of South Africa South Africa (2015).

65 South African Department of Environmental Affairs (2016a).

66 South African Department of Environmental Affairs (2017). 
- the establishment of a National Greenhouse Gas Emissions Reduction Trajectory;

- using the trajectory to inform the imposition of sectoral emissions targets for certain government departments (i.e. for overall sectors such as 'energy' and 'transport') and legally binding individual carbon budgets for individual entities which have high GHG emissions;

- a carbon tax implemented through the National Treasury;

- a monitoring and evaluation regime for GHGs; and

- plans to mitigate GHGs: the formal declaration of six GHGs under the existing legislation as priority pollutants which triggers the obligation on individual high emitting industries to create pollution prevention plans, describing how emissions will be controlled and reduced, over time.

Concerning the National Greenhouse Gas Emissions Reduction Trajectory, various trajectories have been established in terms of the abovementioned policies and South Africa's NDC, but its development and implementation are currently not contemplated by any existing legislation. It is likely that this issue will be addressed in the proposed Climate Change Bill. Similarly, the sectoral emissions targets and carbon budgets require legislation to be implemented as the existing legal regime does not cater for them. Conerning the carbon tax, legislation to bring it into effect has been drafted and the second iteration of a Carbon Tax Bill was published for public comment in December 2017. With regard to GHG monitoring, evaluation and mitigation, several relevant regulations have been published under NEMAQA including: the National Greenhouse Gas Emission Reporting Regulations, ${ }^{67}$ which came into operation on 3 April 2017 (as read with the technical guideline) $;{ }^{68}$ the Declaration of Greenhouse Gases as Priority Pollutants; ${ }^{69}$ and the National Pollution Prevention Plans Regulations. ${ }^{70}$ The intention is for these regulations to apply as an interim measure until 2020, after which time a final Climate Change Act will have ideally been promulgated by Parliament. The intention is then for the above regulations promulgated under NEMAQA to be revised and re-promulgated under the future Climate Change Act. The above five components are discussed in more detail below. 
4.1.1 Emissions reduction trajectory, sectoral emissions targets and carbon budgets

According to the Draft Post-2020 Mitigation Systems Report (2017), it is intended for a national emissions trajectory to be set. ${ }^{71}$ It is likely that the legal mechanisms to support the setting and subsequent use of the trajectory in decision making will be dealt with under the Climate Change Bill.

The emissions trajectory will then be translated into sectoral emissions targets $-{ }^{72}$

that cover all GHG emissions within the South Africa economy and represents the cumulative amount of emissions that can be emitted within a specific time period (i.e. the area under the curve for the emissions trajectory).

Relevant national government departments will be responsible for ensuring these targets are achieved. According to the Draft Post-2020 Mitigation Systems Report (2017), these departments are likely to do so through the development of policies and measures (PAMs) which are to be set out in a plan. Again, it is envisaged that the empowering provisions and relevant rights and duties regarding these plans will be contained in the Climate Change Bill. Provinces and municipalities will also be required to develop plans which support the achievement of these targets. ${ }^{73}$

It is understood that carbon budgets will, effectively, operate as a cap on GHG emissions from a particular installation. It is likely that legislative mechanisms will make it an offence to exceed the cap and to impose a related penalty in the event of conviction. Again, the empowering provisions for carbon budgets (which effectively take away existing rights) will need to be prescribed in law and are likely to be in a proposed Climate Change Bill. There is still considerable debate whether and how, after 2020, the carbon tax and carbon budgets will be aligned. It is possible that instead of a criminal penalty that the carbon tax is used as a compliance mechanism for exceeding a carbon budget. However, this remains to be clarified by the Department and National Treasury.

71 At present, the National Benchmark Emissions Trajectory is based on the 'Peak, Plateau and Decline' trajectory defined in 2010. The final emissions trajectory has not yet been set but will most likely be aligned to South Africa's commitments under the Paris Agreement. The Department's Draft Post-2020 Mitigation Systems Report (2017) defines emission trajectories as “....alternative computations of the likely quantity and trend of greenhouse gas emissions released for a given period, including variances related to levels of economic growth, the structural makeup of an economy, demographic development and the effect of emission reduction policies". Under this analysis, projections were made for 2020, 2030 and 2050 with projected GHG emissions trajectories categorised by the sectors, energy, transport (as a subcategory of energy), industrial processes and products use, agriculture forestry and other land use, and waste.

72 South African Department of Environmental Affairs (2017: 56).

73 Ibid. 


\subsubsection{Carbon tax}

For many years, National Treasury has insisted that it intends to implement a carbon tax in order to reduce South Africa's GHG emissions. On 2 November 2015, following a series of policies and related documents on the topic, ${ }^{74}$ the first draft of a Carbon Tax Bill was published for public comment. This was later accompanied by a set of Draft Carbon Offsets Regulations. ${ }^{75}$ A revised Carbon Tax Bill was published on 14 December 2017. In early 2018, it was announced that the tax would come into effect in January $2019 .{ }^{76}$

The tax is intended to be implemented in phases with the first phase designed to be revenue-neutral. ${ }^{77}$ The tax is a tax on fossil fuel inputs. Entities which conduct listed activities in the schedule to the Bill which emit GHGs above a prescribed threshold (also in the schedule) are tax liable. The proposed headline carbon tax (which is subject to review) is $\mathrm{R} 120$ per ton of $\mathrm{CO}_{2}$ e for emissions above the tax-free thresholds. ${ }^{78}$ The intention was to introduce the tax at a relatively low rate and increase it incrementally over time to reduce its impact on the economy whilst simultaneously giving certainty to the industry with time to adjust. Liable entities can reduce their tax liability by making use of various allowances available under the Bill. ${ }^{79}$ The total amount of allowances can be as high as $95 \%$ in the first phase (which is likely to run until 2022). The Explanatory Memorandum to the revised Carbon Tax Bill (2017) anticipates that as a result, the effective tax rate will be as low as $\mathrm{R} 6$ to $\mathrm{R} 48$ per ton $\mathrm{CO}_{2} \mathrm{e}$. It is intended for the South African Revenue Authority to implement the tax. However, their systems will be aligned with the Department's in order to verify reported emissions.

Unfortunately, notwithstanding much deliberation between the Department and National Treasury, there is still no certainty as to how the carbon tax and carbon budgets

74 South African National Treasury (2006, 2010, 2013, 2014 and 2017); South African Department of Environmental Affairs (2011 and 2017); Partnership for Market Readiness (2014, 2016 and 2017); South African National Treasury Draft Carbon Tax Bill (2015); Davis Tax Committee (2015); National Treasury Draft Carbon Offsets Regulations (2016); Van Heerden et al. (2016: 714).

75 South African National Treasury (2016, the proposed draft Regulations have not yet been published in the Gazette).

76 South African National Treasury (2018: 47).

77 Revenues are likely to be recycled by way of reducing the current electricity generation levy, credit rebate for the renewable energy premium, and a tax incentive for energy efficiency savings.

78 The carbon tax liability will be calculated as the tax base (total quantity of GHG emissions from combustion, fugitive and industrial processes proportionately reduced by the tax-free allowances) multiplied by the rate of the carbon tax.

79 A basic tax-free allowance of $60 \%$; an additional tax-free allowance of $10 \%$ for process emissions; an additional tax-free allowance of $10 \%$ for fugitive emissions; a variable tax-free allowance for trade-exposed sectors (up to a maximum of 10\%); a maximum tax-free allowance of $5 \%$ for above average performance; a 5\% tax-free allowance for companies with a carbon budget; and a carbon offset allowance of either $5 \%$ or $10 \%$. 
will be aligned. The former is a fiscal instrument using the market to drive behaviour and prescribing, in advance, the financial value associated with mitigating GHG emissions. In other words, it creates a carbon price of approximately $\mathrm{R} 120 / \mathrm{CO}_{2} \mathrm{e}$ ab initio, taking into account allowances. Carbon budgets, on the other hand, do not establish a carbon price directly, but rather use the threat of punitive regulatory sanctions to incentivise behaviour, and the cost of compliance as compared to the quantum of the criminal penalty then creates a parallel financial value for reducing GHG emissions. Although not impossible to implement simultaneously, it is a highly unique regime combining both a regulatory and fiscal instruments to achieve a reduction in the same set of GHG emissions. This design will require careful harmonisation to avoid unwanted or unanticipated macroeconomic and environmental impacts.

\subsubsection{Monitoring, evaluation and planning}

Pending the finalisation of the post-2020 carbon budget/sectoral emissions target regime, the Department is building the architecture of the monitoring and reporting regime for GHGs. This will enable a more accurate determination of GHG emissions at a national level and will likely also be used as a basis to determine carbon budgets and potentially to support South Africa's position in the international negotiations on climate change. To this end, the Department published National Greenhouse Gas Emissions Reporting Regulations, ${ }^{80}$ which came into effect on 3 April 2017. They were published under NEMAQA, South Africa's air quality management legislation. They apply to private sector GHG emitting entities that: (i) fall into the sectors specified in the annexure to the Regulations; and (ii) which have an installed capacity above a prescribed capacity threshold. The Regulations require these entities to register, monitor and report certain prescribed information regarding their GHG emissions, specifically information regarding process, fugitive and combustion emissions from all GHG emission sources and source streams.

The Department has also used NEMAQA to require emitters to manage GHG emissions, pending the finalisation of the Climate Change Bill. On 21 July 2017, the Minister declared six GHGs originally identified under the Kyoto Protocol as necessitating reduction, as 'priority pollutants' under NEMAQA (the Declaration). ${ }^{81}$ NEMAQA enables the Minister to declare priority pollutants if they are substances which 'contribute to air pollution'. ${ }^{82}$ Upon declaring a substance a priority pollutant, identified entities are required to submit pollution prevention plans under NEMAQA.$^{83}$ In terms of the

80 Government Gazette 40762 GN 275 of 3 April 2017.

81 Declaration of Greenhouse Gases as Priority Air Pollutants (Government Gazette 40996 GN 710 of 21 July 2017).

82 Section 29(1)(a) of NEMAQA.

83 Section 21(1)(b) of NEMAQA. 
Declaration, entities which undertake the production processes set out in its annexure, which emit more than $0.1 \mathrm{Mt}$ of $\mathrm{CO}_{2} \mathrm{e}$, are required to submit a pollution prevention plan to the Minister for approval and must subsequently monitor and report on its implementation. ${ }^{84}$ It is up to the emitting entity to propose its own set of 'mitigation measures ${ }^{85}$ in the plan, subject to the qualification that the Minister can reject the plan and require revision if these are considered inadequate.

The Declaration was published together with the National Pollution Prevention Plan Regulations (2017) ${ }^{86}$ which set out the prescribed scope and content of a pollution prevention plan, and requirements for the submission of an annual progress report. It is only an offence to fail to comply with the obligation to submit a plan or an annual progress report or to submit false and misleading information, with a fine of up to ZAR5 million and/or five years imprisonment. It is not, however, an offence to fail to implement the mitigation measures approved in the plan itself. As such this system will ultimately be replaced by the carbon budgets regime in 2020, at which time the non-binding mitigation measures in the pollution prevention plan will be replaced by an effective legislated cap on emissions.

\subsection{Adaptation}

At present, there are no existing draft or final laws which regulate adaptation in South Africa. It is intended for these issues to be addressed in the proposed Climate Change Bill, where it is likely that the primary responsibility for increasing resilience and reducing vulnerability will fall upon identified government sectors, provinces and municipalities. It is anticipated that these sectors and spheres of government will have to undertake vulnerability assessments and devise plans in order to respond to the impacts anticipated in these assessments. It is also likely that the Climate Change Bill will to some degree facilitate the realisation of the adaptation related commitments made by South Africa in its NDC under the Paris Agreement. These include the development of a National Adaptation Plan (a draft plan has already been circulated for public comment); the inclusion of climate change considerations in sub-national and cross-sector policy frameworks; the building of institutional capacity; and the development of an early warning, vulnerability and adaptation monitoring system. The NDC also contemplates the creation of various assessments and frameworks including a national

84 Regulation 4 and 5.

85 Specifically, it must contain a "description of migration measures, based on the best information available at [the] time, that will be implemented and result in [a] deviation from the greenhouse gas emissions baseline over the pollution prevention plan's period, and the projected emissions reductions that will be achieved" (Regulation 3(1)(f)).

86 National Pollution Prevention Plan Regulations (Government Gazette 40996 GN 712 of 21 July 2017). 
vulnerability assessment, and adaptation needs framework as well as an adaptation communication, education and awareness framework. As noted earlier in this chapter, the Bill can play an empowering role by mandating the prescribed contents of such plans and frameworks, identifying the responsible state actors for their creation, specifying their period of review and requiring a public participation process.

Like South Africa, Kenya's climate change regulatory framework grew from a robust set of policies setting out Government's intention on how to manage the county's emissions and adapt to anticipated impacts. The most important of these is the $2010 \mathrm{Na}-$ tional Climate Change Response Strategy (NCCRS) ${ }^{87}$ which was operationalised by the National Climate Change Action Plan 2013-2017 (NCCAP) ${ }^{88}$ and the National Adaptation Plan 2015-2030 (National Adaptation Plan). ${ }^{89}$ One of the key focuses of the NCCRS developed in 2010, was the mainstreaming of climate change considerations into policies and plans. It recommended the development of a comprehensive climate change policy which would serve as a platform for the development of a climate change statute. It proposed that this could be either in the form of amendments to existing laws or the development of a framework law, with a preference expressed for the latter. ${ }^{90}$ In March 2013, an Action Plan was developed to operationalise this policy, covering a wide array of issues such as low carbon development; strategies; adaptation and mitigation measures; climate finance; and a policy, legislative, and institutional framework to support the mainstreaming of climate change considerations. ${ }^{91}$

Kenya's NDC under the Paris Agreement ${ }^{92}$ contains a number of mitigation and adaptation objectives as well. The country is seeking to reduce GHG emissions by $30 \%$ by 2030 relative to the business as usual scenario of $143 \mathrm{MtCO}_{2}$ eq, and the NDC proposes various actions to achieve this target. To enhance resilience, one of the focal adaptation actions is to 'mainstream' climate change adaptation into medium-term plans and implement adaptation actions. Priority adaptation actions are elaborated upon in the National Adaptation Plan. Climate change actions are also currently being considered under the medium-term planning process to implement Kenya's national

87 Kenyan Ministry of Environment and Natural Resources (2010).

88 Kenyan Ministry of Environment and Natural Resources (2013).

89 Kenyan Ministry of Environment and Natural Resources (2015a).

90 Kenyan Ministry of Environment and Natural Resources (2010: 6). See also the summary provided by Oulu (2015: 230).

91 Oulu (2015: 230).

92 Kenyan Ministry of Environment and Natural Resources (2015b: 2-6). 
planning instrument: Vision 2030, which guides the implementation of Kenya's NDC..$^{93}$

In May 2016, soon after the conclusion of the Paris Agreement, Kenya passed the Kenyan Climate Change Act. The Act is primarily focused on the creation of institutional structures and the 'mainstreaming' of climate change actions within government. It creates three institutional mechanisms. The first is the National Climate Change Council which is chaired by the President, with the Cabinet Secretary responsible for Climate Affairs as its Secretary. The Secretary is supported by the Climate Change Directorate. This leadership role demonstrates the cross-cutting nature of climate change and is a useful example of how the elevation of governance functions to the level of the Presidency, can serve to overcome sectoral challenges within climate change governance. This Council is responsible for "ensuring the mainstreaming of climate change functions by the national and county governments" and must "approve and oversee the implementation of the National Climate Change Action Plan". ${ }^{94}$ By extension, this also includes the oversight and mainstreaming of adaptation and mitigation functions and also the implementation of the National Adaptation Plan. ${ }^{95}$ It is also required to provide "guidance on [the] review, amendment and harmonisation of sectoral laws and policies in order to achieve the objectives of [the] Act" and to set targets for the regulation of GHGs. ${ }^{96}$

The Cabinet Secretary has various powers and duties, including the provision of technical assistance on climate change actions and responses to County Governments. The Cabinet Secretary is also obliged to develop, review and update the NCCAP, and to report biennially to Parliament on the status of implementation of international and national obligations, and progress achieved towards attaining low carbon and climate resilient development. ${ }^{97}$ The Act also creates the Climate Change Directorate as the lead agency of government on national climate change plans, and which reports to the Cabinet Secretary. ${ }^{98}$ It also plays a coordinating role and will provide technical assistance on climate change actions and responses to County Governments. It has a relatively wide responsibility for "set[ting] targets and coordinat[ing] actions for building resilience to climate change and enhancing adaptive capacity, and the undertaking of a biennial review of the implementation of the NCCAP and reporting to the Council". 99 Lastly, the Act creates the Kenya Climate Fund to be a financing mechanism for

Statement by Wakhungu, Ministry of Environment and Natural Resources, Kenya to the UNFCCC, at <http://unfecc.int/files/meetings/bonn_nov_2017/statements/application/pdf/kenya_ cop23cmp13cma1-2_hls.pdf> (accessed 20-12-2017).

95 Kenyan Ministry of Environment and Natural Resources (2016: 10).

96 Section 6(f) of the Climate Change Act (2016).

97 Section 8 of the Climate Change Act (2016).

98 Section 9 of the Climate Change Act (2016).

99 Section 9(8) of the Climate Change Act (2016). 
prioritised climate change actions and interventions that have been approved by the Council. ${ }^{100}$

The Act prescribes the content of the NCCAP, ${ }^{101}$ with relatively general objectives, mostly towards increasing resilience, low carbon sustainable development and the mainstreaming of climate change actions. The Council also has the power to impose 'climate change duties' on the public sector. ${ }^{102}$ State departments and other national entities also have a duty to mainstream climate change considerations into existing strategies and plans, to report on sectoral GHG emissions for a national inventory, to create a designated unit within each department to coordinate the mainstreaming of climate change in that body, with related functions for monitoring and reporting. In particular, there is a detailed process for performance review of climate change functions by these bodies, ultimately involving the National Assembly. ${ }^{103}$ The Act also empowers the Council to impose "climate change obligations on private entities", 104 and to make regulations regarding monitoring and the evaluation of compliance with such obligations. The Act does not specify what such obligations may be, but presumably, they entail limitations on GHG emissions and potentially also adaptation actions. The Act also places a duty upon the National Environmental Management Authority, on behalf of the Council, to monitor and report on compliance by public and private entities on their assigned climate change duties, and the extent of "compliance on levels of greenhouse gas emissions as set by the Council under this Act". ${ }^{105}$

Lastly, there are extensive provisions on how 'mainstreaming' is to be achieved by other spheres of government, including: the mainstreaming of climate change considerations into 'functions and budgets' of relevant state departments and entities; the performance of all functions by County Governments; Country Integrated Development Plan and Country Sectoral Plans; the integration of climate risk and vulnerability assessments into all forms of assessments (e.g. EIAs); and into the national education curriculum. ${ }^{106}$

Whilst it would be simplistic to assume that the above regulatory and statutory references serve as a measure of best practice for the continent, it is useful to consider

100 Section 25 of the Climate Change Act (2016).

101 Section 13(3) of the Climate Change Act (2016).

102 Section 15 of the Climate Change Act (2016).

103 Section 15(6)-(10) of the Climate Change Act (2016).

104 Section 16 of the Climate Change Act (2016).

105 Section 17 of the Climate Change Act (2016).

106 Section 18-21 of the Climate Change Act (2016). 
common themes and some examples which are, in the author's view, elements of good practice.

Clearly, both countries have sought to pursue framework laws instead of sectoral amendments. This seems to be the prevalent theme for other African countries in any event, as discussed in Part 3 above, where Uganda, Zambia and Nigeria are all in the process of considering the development of framework laws. The Kenyan example is easier to illustrate, simply because it has been able to crystallise climate policy in a framework law before South Africa was able to. In each instance, however, the benefits of a framework law become immediately apparent.

The framework law can create an institution to guide the development and implementation of climate change policy and 'mainstreaming', with a view to harmonising state action and ensuring a coordinated response. Kenya's escalation of this function to the level of the Presidency is a particularly useful example of the need to prioritise climate change actions across sectors and to afford it the necessary gravitas of political will. As Oulu suggests, fragmentation, conflicting mandates and capacity challenges plague many developing country institutions, and for this reason, the creation of climate change specific institutions (notably at this level) is particularly useful. ${ }^{107}$

The detailed function of the Kenyan Council and the focus on the need for appropriately technically qualified experts across a wide array of disciplines (for example in the Directorate) ${ }^{108}$ create a politically and technically balanced forum that is sufficiently robust against political flux.

Commentators have argued that successful climate change legislation must be simultaneously flexible in certain respects and steadfast in others. ${ }^{109}$ This means that it should incorporate institutional design features that significantly insulate implementation from vested political and economic interests. The Kenyan example is a useful example of such legislation. Oulu puts the argument well when he argues for design features such as "pre-commitment strategies which deliberately make it hard, though not impossible, to change the law in response to emerging concerns and insights, as well as those intended to keep the statute on course over time". ${ }^{110}$ One way in which this is achieved in Kenya is through the deep mainstreaming of climate change considerations across sectors and spheres of government in a way that makes it difficult to reverse because of its scope and depth. Similarly, the elevated quasi-legislative status of the Kenyan NCCAP and its prescribed content makes it less vulnerable to political whim and neglect.

Oulu also cites other examples of best practice such as "requirements for consultation with other agencies, scientific advisory committees, and stakeholders; judicial

107 Oulu (2015: 230).

108 See for example the qualification requirements in Section 9(4).

109 Lazarus (2008: 1153).

110 Oulu (2015: 231). 
review provisions; and pre-emption triggers that accommodate competing interests while exploiting the resulting tension to further climate change policy". ${ }^{111}$ Kenya achieves some of this through the appointment of technically qualified staff in the Directorate (as specified in the Act), public consultation provisions, ${ }^{112}$ and the right to approach the Environmental and Land Court for climate change specific complaints with a reduced burden of proof. ${ }^{113}$

A common theme across the Kenyan Climate Change Act is also the need for mainstreaming. If the Act had to be summarised in one word it would probably be that. South Africa's NCCRP, the National Adaptation Plan and related government policies also place a particular emphasis on mainstreaming climate change considerations, and it is likely to play an important role in the South African Climate Change Bill. As discussed above, not only does mainstreaming protect against political inaction or a change in policy, but it also overcomes some of the cross-sectoral and intra-governmental challenges which beset any government when addressing climate change. It ensures that there is an uptake in action by all relevant spheres and sectors, ensuring buy-in and coordination, and it also recognises the need for climate change responses to be driven by a multitude of actors in both the private and public sphere. Whilst mitigation can, to some degree, be driven by one state department through, for example, the South African approach of creating sectoral GHG targets and carbon budgets, adaptation requires a much wider array of actors to be effective. Mainstreaming is possibly one of the most useful instruments to include in a Climate Change Act particularly in Africa where adaptation is a pressing and urgent priority. The way that this has been achieved in the Kenyan Climate Change Act and its detailed provisions identifying the specific planning instruments requiring mainstreaming, together with its definition of mainstreaming is considered particularly useful.

One issue the Kenyan Climate Change Act is relatively unclear on is the nature and process for imposing limitations on GHG emissions. The Act speaks of the Council needing to set targets for the regulation of GHGs, state departments reporting on sectoral GHGs, and a general reference to 'climate change obligations' which can be imposed on private entities. Potentially this issue may be captured in regulations under the Act. By comparison, the South African regulatory regime, including the proposed carbon tax, the current monitoring and reporting regulations for the purposes of a GHG inventory, coupled with the duty to create a pollution prevention plan, as well as the extensive architecture for the emissions trajectory, carbon budgets and sectoral emissions targets is a relatively more advanced example of GHG mitigation regulation.

111 Oulu (2015: 231).

112 Section 24 of the Climate Change Act (2016).

113 Section 23 of the Climate Change Act (2016). There is no need to demonstrate loss or injury in such complaints. 
This is likely symptomatic of the fact that South Africa emits considerably more GHGs per capita than Kenya, ${ }^{114}$ and accordingly, there is a greater impetus to regulate these emissions in the near future. Whilst this approach may seem premature for many African countries, many of which have similarly low emissions profiles to Kenya, the author believes that it is a useful and necessary legislative regime to at least consider when developing a Climate Change Act, mindful that instituting early action on the regulation of GHGs will not only facilitate the achievement of African country commitments under their NDCs, but it will facilitate the adoption of low carbon technologies within the earlier phases of development thereby reducing future retrofit and compliance costs. The costs of low carbon technologies are also becoming increasingly competitive and as such may not in themselves always be an impediment to development if adopted at an early phase.

This is not to suggest that African countries should pursue the extensive and complicated carbon budget/carbon tax scheme proposed by South Africa, but it is helpful to consider the development of an inventory, implementing monitoring and reporting requirements in regulations and an architecture for GHG emissions targets/allowances within the empowering legislation at an early stage. As the Grantham Institute suggests: ${ }^{115}$

.... good evidence base for informed climate policy requires data about both emissions and climate risks, as well as about options to reduce emissions and improve resilience to climate change. A key plank of good climate change legislation is therefore a detailed greenhouse gas inventory consisting of compulsory, timely and systematic reporting for greenhouse gases from all sectors as well as regular climate change risk assessments that can inform adaptation measures.

Similarly, they advocate the use of GHG emissions targets as a means to "set a longterm trajectory and send a signal of political intent to business and civil society". ${ }^{116}$

Lastly, one common theme is that both regulatory developments grew from a sound, well researched and detailed set of policies and strategies. In both cases, there were more than just one policy or strategy addressing climate change, and both countries had drafted a national adaptation plan underpinned by comprehensive vulnerability assessments. The usefulness of this approach is that it enables detailed and extensive public input into policy (and ultimately regulatory) objectives, ensuring that the law, once developed, is tailored to national circumstances and also has public and political buy-in. This is typically the case in many countries which enact framework laws, and it finds equal relevance on the African continent. As such the first step in the development of any climate change law ideally is the development of a national framework climate change policy or strategy underpinned by a well-informed vulnerability and needs assessment, ideally coupled with an action or implementation plan.

114 In 2014, South Africa emitted $9 \mathrm{Mt} /$ capita, compared to Kenya which emitted $0.3 \mathrm{Mt} /$ capita, see $<$ https://data.worldbank.org/indicator/EN.ATM.CO2E.PC.> (accessed 20-12-2017).

115 Nachmany et al. (2015).

116 Ibid. 
Climate change legislation plays an important role in spurring action, operationalising climate change policy and also shielding it from policy change. Certainly, it has its challenges, and its nature varies greatly. The risk of subsequent amendments, budgetary limitations, delays in bringing regulations into effect, vested interests, and a lack of enforcement can render a seemingly strong legal mandate mere symbolic aspirational statement. ${ }^{117}$ Nevertheless, if appropriately crafted and with the necessary political will, climate change laws can play an important and meaningful role in driving a national response.

Countries across Africa are in the process of developing climate change laws, primarily in framework form, to address the anticipated impacts of climate change and to facilitate low carbon development. Framework laws have proven to be durable instruments with the advantage that they facilitate mainstreaming and the development of cross-sectoral institutions. The Kenyan example is a useful prototype of how both of these objectives can be achieved, and it is anticipated that South Africa will follow a similar route. The South African example is also a helpful demonstration of how to create a relatively detailed regulatory architecture for the management of GHG emissions and the related mechanisms to develop an inventory, trajectory and ultimately GHG emissions thresholds.

It would not be appropriate to simply duplicate these examples when developing national legislation and regulations. However, it is encouraging to see national responses that are relatively advanced and nuanced on the continent and which speak to immediate challenges. It has been shown that the propensity to legislate is heavily influenced by the passage of similar laws elsewhere, suggesting a strong role for peer pressure or learning effects. ${ }^{118}$ This will hopefully be the case for climate change legislation in Africa where national influences can foster regional growth in climate change laws. Going forward, and mindful of the relative youth of this field of law, it is hoped that these developments will cross-pollinate each other and build a robust set of laws to drive climate change action nationally, regionally and across the continent.

\section{References}

Arounusi, Q (2017) “Green party petitions to present a Bill on implementation of zambia's commitments on climate change" Lusaka Times (8-1-2017), at <https://www.lusakatimes.com/ 2017/01/08/green-party-petitions-parliament-present-bill-implementation-zambias-commitments -climate-change/> (accessed 20-12-2017).

117 Oulu (201: 231).

118 Fankhauser et al. (2014). 
Averchenkva, A \& S Matikamen (2017) "Climate legislation and international commitments" in A Averchenkova, S Fankhauser \& M Nachmeny (eds) Trends in climate change legislation.

CAHOSCC / Committee of African Heads of States and Governments on Climate Change (2014) Work programme on climate change action in Africa.

Craig, R (2010) "Stationarity is dead - long live transformation: five principles for climate change adaptation law" 34 Harvard Environmental Law Review 9-75.

Danmaryam, H (2017) “Trade unions, CSOs, academia, make input into Climate Change Bill” EnviroNews Nigeria (20-7-2017), at <http:/www.environewsnigeria.com/trade-union-csos-academiamake-input-climate-change-bill/> (accessed 20 December 2017).

Davis Tax Committee (2015) First interim report on the proposed carbon tax for South Africa.

Fankhauser, S, C Gennaioli \& M Collins (2014) Domestic dynamics and international influence: What explains the passage of climate change legislation? Policy Working Paper No. 156 Grantham Research Institute on Climate Change and the Environment and Centre for Climate Change Economics, at <http://www.lse.ac.uk/GranthamInstitute/wp-content/uploads/2014/05/Wp156Domestic-dynamics-and-international-influence-what-explains-the-passage-of-climate-changelegislation.pdf $>$ (accessed 20-7-2017).

Gilder, A \& O Rumble (2017) “Africa, current developments in carbon and climate law" 3 Climate and Carbon Law Review 268-271.

Government of South Africa (2015) South Africa's intended nationally determined contribution under the Paris Agreement.

IPCC / Intergovernmental Panel on Climate Change (2014) Climate change 2014: impacts, adaptation, and vulnerability: contribution of Working Group II to the Fifth Assessment Report of the Intergovernmental Panel on Climate Change [VR Barros, CB Field, DJ Dokken, MD Mastandrea, KJ Mach, TE Bilir, M Chatterjee, KL Ebi, YO Estrada, RC Genova, B Girma, ES Kissel, AN Levy, S MacCracken, PR Mastrandrea \& LL White (eds)].

Iroanusi, Q (2017) "Nigeria: house moves to establish Climate Change Council” Premium Times (207-2017), at <http://allafrica.com/stories/201707210026.html> (accessed 20 December 2017).

Kenyan Ministry of Environment and Natural Resources (2010) National climate change response strategy.

Kenyan Ministry of Environment and Natural Resources (2013) National climate change action plan 2013-2017.

Kenyan Ministry of Environment and Natural Resources (2015a) National adaptation plan 20152030.

Kenyan Ministry of Environment and Natural Resources (2015b) Kenya's intended nationally determined contribution (INDC) (23-6-2015), at $<\mathrm{http}$ :/www4.unfccc.int/ndcregistry/Published Documents/Kenya\%20First/Kenya_NDC_20150723.pdf $>$ (accessed 20-12-2017).

Klass, A (2013) "Climate change and the convergences of environmental and energy law" XXIV Fordham Environmental Law Review 180-275.

Knox, J (2009) "Linking human rights and climate change at the United Nations" 33(2) Harvard Environmental Law Review 477-498.

Lazarus, R (2008) "Super wicked problems and climate change: restraining the present to liberate the future" 94 Cornell Law Review 1153-1233.

McDonald, J \& M Styles (2014) "Legal strategies for adaptive management under climate change" 26(1) Journal of Environmental Law 25-53.

Nachmany, M, S Fankhauser, J Davidová, N Kingsmill, T Landesman, H Roppongi, P Schleifer, J Setzer, A Sharman, C Stolle Singleton, J Sundaresan \& T Townshend (2015) The 2015 global 
climate legislation study, at <http://www.lse.ac.uk/GranthamInstitute/wp-content/uploads/2015/ 05/Global_climate_legislation_study_20151.pdf> (accessed 17-7-2018).

Nachmany M, S Fankhauser, J Setzer \& A Averchenkova (2017) Global trends in climate change legislation and litigation: 2017 update, at <http:/www.lse.ac.uk/GranthamInstitute/wp-content/ uploads/2017/04/Global-trends-in-climate-change-legislation-and-litigation-WEB.pdf $>$ (accessed 20-12-2017).

OHCHR / Office of the United Nations High Commissioner for Human Rights (2009) Report of the Office of the United Nations High Commissioner for Human Rights on the relationship between climate change and human rights (U.N. Doc. A/HRC/10/61 (15-1-2009)), at $<$ http://www.ohchr. org/Documents/Press/AnalyticalStudy.pdf $>$ (accessed 20-12-2017).

Osofsky, H \& L McAllister (2012) Climate change law and policy.

Oulu, M (2011) "Mainstreaming climate adaptation in Kenya" 2(3) Climate Law 375-394.

Oulu, M (2015) "Climate change governance: emerging legal and institutional frameworks for developing countries" in W Filhou (ed.) The handbook of climate change adaptation 227-250.

Parliamentary Communication Services (2017) "Environmental Affairs Portfolio Committee encouraged to hear that climate change legislation will soon be introduced in Parliament" (10-10-2017), at $<$ https://www.parliament.gov.za/press-releases/environmental-affairs-portfolio-committee-encouraged-hear-climate-change-legislation-will-soon-be-introduced-parliament> (accessed 20-122017).

Partnership for Market Readiness (2014) Emissions intensity benchmarks for the South African carbon tax-technical support study.

Partnership for Market Readiness (2016) Modelling the impact on South Africa's economy of introducing a carbon tax.

Partnership for Market Readiness (2017) Integration of the carbon tax and carbon budgets in South Africa.

Phillips, G "Paris Agreement on climate change places Africa at the fulcrum of renewable energy deployment, experts agree" African Development Bank Group (29-03-2016), at $<$ https://www.afdb.org/en/news-and-events/paris-agreement-on-climate-change-places-africa-atthe-fulcrum-of-renewable-energy-deployment-experts-agree-15531/> (accessed 20-12-017).

Rumble, O (2016) "Water resource management and climate change" in T Humby, L Kotze, O Rumble \& O Gilder (eds) Climate change law and governance in South Africa 9(1)-9(31).

South African Department of Environmental Affairs (2004) National climate change response strategy.

South African Department of Environmental Affairs (2011) National climate change response white paper.

South African Department of Environmental Affairs (2013) Long-term adaptation scenarios flagship research programme (LTAS) - Phase 1 .

South African Department of Environmental Affairs (2014) South Africa's greenhouse gas (GHG) mitigation potential analysis.

South African Department of Environmental Affairs (2015) Long-term adaptation scenarios flagship research programme (LTAS) - Phase 2.

South African Department of Environmental Affairs (2016a) South Africa's draft national adaptation strategy.

South African Department of Environmental Affairs (2016b) Technical guidelines for monitoring, reporting and verification of greenhouse gas emissions by industry - a companion to the South African National GHG reporting regulations (Version No. TG-2016.1). 
South African Department of Environmental Affairs (2017) Development of South Africa's post-2020 climate change mitigation system draft report.

South African National Treasury (2006) A framework for considering the use of market-based instruments to support environmental fiscal reform in South Africa.

South African National Treasury (2010) reducing greenhouse gas emissions: the carbon tax option.

South African National Treasury (2013) Carbon tax policy paper: reducing greenhouse gas emissions.

South African National Treasury (2014) Carbon offsets.

South African National Treasury (2016) Proposed regulations: carbon offsets (not yet published in the Gazette).

South African National Treasury (2018) Budget review.

Tashobya, A (2017) "Rwanda: revised law equips climate fund to mobilise resources" The New Times (25-8-2017), at <http://allafrica.com/stories/201708250012.html> (accessed 20-12-2017).

The World Bank (2017) " $\mathrm{CO}_{2}$ emissions (metric tons per capita)", at $<$ https://data.worldbank.org/indicator/EN.ATM.CO2E.PC.> (accessed 20-12-2017).

Townshend, T, S Frankhauser, A Matthews, A Feger, J Liu \& T Narciso (2011) "Legislating climate change on a national level" 53(5) Environment: Science and Policy for Sustainable Development 5-17.

Townshend, T, S Fankhauser, R Aybar, M Collins, T Landesman, M Nachmany \& C Pavese (2013) "How national legislation can help to solve climate change" 3 Nature Climate Change 430-432.

UNECA / United Nations Economic Commission for Africa (2017) "Africa spending more than its fair share for adaptation" (06-11-2017), at <https://www.uneca.org/stories/africa-spending-moreits-fair-share-climate-adaptation-new-study-reveals $>$ (accessed 20-12-2017).

Uwaegnulam, C (2016) "Legislators plan new law to unify climate change policies" The Guardian (15-11-2016), at <https:/guardian.ng/news/legislators-plan-new-law-to-unify-climate-changepolicies/> (accessed 20-12-2017).

Van Heerden, J, J Blignaut, H Bohlmann, A Cartwright, N Diederichs \& M Mander (2016) “The economic and environmental effects of a carbon tax in South Africa: a dynamic CGE modelling approach" 19(5) South African Journal of Economic and Management Sciences 714-732.

Williams, R (2017) “The UK Climate Change Act: standing strong in a time of change" (6-04-2017), at $<$ https://sandbag.org.uk/2017/04/06/uk-climate-change-act-standing-strong-time-change/ $>$ (accessed 20-12-2017).

Winkler, H (2007) (ed.) Long term mitigation scenarios: technical report, Prepared by the Energy Research Centre for Department of Environment Affairs and Tourism. 